\title{
A preference technique to investigate visual acuity in the rat'
}

\begin{abstract}
Hooded rats were placed on a center board with a plain surface (black or white) under glass on one side and a black and white striped pattern (parallel or perpendicular to the center board) under glass on the other. Striations of $1 / 4 \mathrm{in}, 1 / 8$ in and $1 / 16$ in were used. Ss descended from the center board to the $1 / 4$ in and $1 / 8$ in stripes significantly more frequently than to the plain surface, not significantly so for the $1 / 16$ in stripes. This experiment agrees in general with Lashley's conclusions on the limits of acuity in the hooded rat, and it shows that a preference technique that requires no training can be used to investigate visual acuity.

\section{Problem}

This experiment is an attempt to test for visual acuity in the hooded rat in a preference situation where the $\mathrm{S}$ has a choice of descent from a center board to a striped pattern or to a plain surface. Walk (1965) used hooded rats in a visual-cliff-like testing situation with checked patterns directly under the glass on one side of the center board and a plain surface under glass on the other. Ss descended predominantly to the checked pattern until $1 / 14$ in checks were used. Then, Ss decended to the checks over the plain gray but to the plain black over the checks. Lashley's (1930) experiment with the hooded rat showed acuity of 26-52 min. of arc. Using the Lashley jumping stand, with the $\mathrm{S} 20 \mathrm{~cm}$ (7.9 in) from the stimuli, he found discrimination of $3 \mathrm{~mm}$ horizontal stripes over vertical stripes and failure on $1.5 \mathrm{~mm}$ stripes. Translated into the visual cliff situation, where the $S$ is about 5 in above the glass, Lashley's discrimination "success" was to about 1/13 in stripes and "failure" was to approximately $1 / 27$ in stripes. The number of Ss in the Walk (1965) study was small, however. The present experiment is an extension of it using horizontal and vertical striations compared to nontextured surfaces.

The $\mathrm{S}$ was placed on a center board with a striped pattern on one side of it and a plain surface on the other. Stripes of $1 / 4 \mathrm{in}, 1 / 8 \mathrm{in}$, and $1 / 16$ in were presented, either parallel to the center board or perpendicular to it. The plain surface was a homogeneous black or a homogeneous white. The descent of the $\mathrm{S}$, to the striations or to the plain surface, was observed.

\section{Procedure}

Preliminary. Original plans were to use stripes on one side of the center board and no stripes on the other, without any glass, as a better stimulus control.
Several hundred sheets of each stimulus pattern were ordered in order to replace the paper when it was soiled by defecation or urination. This procedure yielded no discrimination in pretests. Discrimination only appeared when the pattern or plain color was placed under the glass.

Subjects. The Ss were a total of 207 adult hooded rats. Of these Ss, 95 had been used in other preference experiments unrelated to visual acuity; the remaining 112 were naive when first tested but 96 of these Ss were tested twice in the acuity experiment. Those tested twice were used in a different condition (always with a different width of stripes and usually with a different orientation of pattern and color of plain surface). This makes statistical tests within acuity conditions independent, but it does not permit combining across acuity situations for statistical tests.

Apparatus. The apparatus was the visual cliff illustrated in Walk (1965), Fig. 1, like a glass bottomed box of $3 / 4$ in pine with outside dimensions 20 in by 32 in and sides 14 in high. Patterns were placed on masonite directly under the glass. The $\mathrm{S}$ was placed on the 4 in by 4 in by 18 in board that bisected the glass. The apparatus, including the center board, was painted gray. On one side of the center board, under the glass, was a homogeneous black or white; on the other side was a striped pattern. Illumination was through white sheeting $5 \mathrm{ft}$ above the apparatus.

Experimental procedure. S was placed on the center board and observed until it descended from the center board to the glass surface or until a $3 \mathrm{~min}$. latency period passed and "no descent" recorded. Horizontal stripes (parallel to the center board) or vertical stripes (perpendicular to the center board) were paired with black or white plain surfaces. For each width of stripes (1/4 in, $1 / 8$ in, or $1 / 16$ in) the 2 by 2 design of horizontal stripes vs. black, horizontal stripes vs. white, vertical stripes vs. black and vertical stripes vs. white was carried out. The position of the stimuli (east or west of the center board) was changed after about 4-6 Ss to balance out possible room preferences. The glass on both sides of the center board was cleaned after each $\mathrm{S}$ was tested.

\section{Results}

The results are shown in Table 1 . Descents to the striped pattern were as follows: $90 \%$ to the $1 / 4$ in stripes, $68 \%$ to the $1 / 8$ in stripes and $62 \%$ to the $1 / 16$ in stripes. Only the overall $1 / 4$ in and $1 / 8$ in comparisons are statistically reliable $(p<.05)$ using the binomial test. 
TABLE I

Descents to Striations or Plain Surfaces with Different Width of Stripes, Orientation of Stripes and Color of Homogeneous Surface

\begin{tabular}{|c|c|c|c|c|c|c|}
\hline \multirow[b]{2}{*}{ Stripe Width } & \multirow[b]{2}{*}{ Comparison } & \multicolumn{3}{|c|}{ Descent to: } & \multirow[b]{2}{*}{ No Desc. } & \multirow{2}{*}{$\begin{array}{c}z \\
\text { (Patt.- } \\
\text { Plain) }\end{array}$} \\
\hline & & $N$ & Pattern & Plain & & \\
\hline \multirow[t]{5}{*}{$1 / 4$ inch } & Horiz. vs. Black & 16 & 11 & 2 & 3 & $2.219^{\star}$ \\
\hline & Horiz. vs. White & 16 & 9 & 1 & 6 & $2.214^{\star}$ \\
\hline & Vert. vs. Black & 16 & 13 & 1 & 2 & $2.940 * \star$ \\
\hline & Vert. vs. White & 16 & 11 & 1 & 4 & $2.598^{\star \star}$ \\
\hline & Totals & 64 & 44 & 5 & 15 & $5.429^{\star \star}$ \\
\hline \multirow[t]{5}{*}{$1 / 8$ inch } & Horiz. vs. Black & 37 & 17 & 6 & 14 & $2.083^{\star}$ \\
\hline & Horiz. vs. White & 37 & 13 & 5 & 19 & 1.649 \\
\hline & Vert. vs. Black & 38 & 12 & 7 & 19 & 0.917 \\
\hline & Vert. vs. White & 36 & 12 & 8 & 16 & 0.671 \\
\hline & Totals & 148 & 54 & 26 & 68 & $3.019 * \star$ \\
\hline \multirow[t]{5}{*}{$1 / 16$ inch } & Horiz. vs. Black & 24 & 9 & 2 & 13 & 1.809 \\
\hline & Horiz. vs. White & 21 & 8 & 3 & 10 & 1.206 \\
\hline & Vert. vs. Black & 23 & 10 & 7 & 6 & 0.485 \\
\hline & Vert. vs. White & 23 & 5 & 8 & 10 & -0.555 \\
\hline & Totals & 91 & 32 & 20 & 39 & 1.525 \\
\hline
\end{tabular}

* $\mathrm{p}<.05 \quad$ ** $\mathrm{p}<.01$

Table 1 also shows a general decline in discrimination effectiveness in the $1 / 8$ in and $1 / 16$ in series from horizontals to verticals and from black to white. Descents to the horizontal striations were $73 \%$ with $1 / 8$ in stripes and $77 \%$ with $1 / 16$ in stripes. Descents to vertical striations were $62 \%$ with $1 / 8$ in stripes and $50 \%$ with $1 / 16$ in stripes. Descents to striations when the plain surface was black were $69 \%$ with the $1 / 8$ in stripes and $68 \%$ with $1 / 16$ in stripes; on the other hand, descents to stripes when the white pattern was present were $66 \%$ for $1 / 8$ in stripes and $54 \%$ for $1 / 16$ in stripes. Only in the vertical $1 / 16$ in stripes compared to white was there more descents to the homogeneous surface than to stripes.

It is possible, then, that near threshold the horizontal (parallel to the center board) striations are more effective as stimuli than the vertical (perpendicular to center board) stripes but, so far, this is only a strong trend. The Ss typically descend at an end of the center board after facing the pattern and bobbing the head up and down. The black pattern seems to be more avoided than the white pattern although the trend is not as marked as is the horizontal-vertical difference. To the human observer the homogeneous black under the glass seems a little more mirror-like and "deeper" than the white surface.

The increase in "no descents" observed in the $1 / 8$ in and $1 / 16$ in situations as compared to the $1 / 4$ in comparison probably reflects the uncertain stimulus situation, but detailed comparison of $1 / 8$ in and $1 / 16$ in on this dimension is hindered by prior experience of some of Ss (prior experience tends to increase the "no descent" category).

\section{Diseussion}

The visual cliff situation can be used to obtain data on the visual acuity of animals. Animals descend to the pattern rather than to the plain surface and this preference becomes less and less marked as the limit of visual acuity is reached.

Fantz (1961) showed that infants will fixate a striped pattern rather than a plain surface and these spontaneous fixations can be used to test the visual acuity of the human infant. The present procedure, like the Fantz procedure, is a voluntary organism-induced response.

The present experiment, when compared to Lashley's (1930), shows more uneven discrimination. He obtained 20 errorless trials with $3 \mathrm{~mm}$ stripes in all five of his pigmented animals. This is about equal to $100 \%$ discrimination of $1 / 13$ in stripes from 5 in away. This experiment gave $68 \%$ preference of $1 / 8$ in stripes and $62 \%$ (not significant) discrimination of $1 / 16$ in striations. The eye of the rat is myopic (Lashley, 1932) and is probably better focused at 5 in (this experiment) than at 7.9 in or $20 \mathrm{~cm}$ (Lashley). The preference procedure is thus a little more variable.

The advantages of the preference procedure, however, are: (1) it permits testing without training; (2) it permits testing of animals too young to be subjected to a training procedure; (3) it permits testing animals when a training procedure takes too much time as in animals just emerged into the light from the dark. Disadvantages of the procedure, as used here, are: (1) it requires a large number of animals; (2) reflections from the glass may distort the "purity" of the stimulus; (3) an S like the rat bobs its head so that the precise distance from which the discrimination is made (here estimated at 5 in) is only approximate.

\section{References}

Fantz, R. L. The origin of form perception. Scient. Amer., 1961, 204 (5), 66-72.

Lashley, K. S. The mechanism of vision: III. The comparative visual acuity of pigmented and albino rats. J. genet. Psychol., 1930, 37, 481-484.

Lashley, K. S. The mechanism of vision: V. The structure and image-forming power of the rat's eye. J. comp. Psychol., 1932, $13,173-200$.

Walk, R. D. The study of visual depth and distance perception in animals. In D. S. Lehrman, R. Hinde and E. Shaw (Eds.), $A d-$ vances in the study of behavior. Vol. 1. New York: Academic Press, 1965. Pp. 99-154.

\section{Note}

1. This research was supported in part by a grant (GB 272) from the National Science Foundation. The assistance of Bernard Karmel and Terese Karmel in carrying out this experiment is gratefully acknowledged. 